\title{
A HIPERTERMIA DURANTE O ESTRO PODE AFETAR O DESEMPENHO REPRODUTIVO DE FÊMEAS SUÍNAS
}

\author{
HIPERTERMIA DURING ESTRUS MAY INFLUENCE THE REPRODUCTIVE \\ PERFORMANCE OF FEMALE PIGS
}

\author{
Ivo Wentz ${ }^{1}$ Fernando Pandolfo Bortolozzo ${ }^{1}$ Guilherme Brandt ${ }^{2}$ Augusto Heck ${ }^{2}$ \\ Paulo Eduardo Bennemann ${ }^{2}$ Antonio Lourenço Guidoni ${ }^{3}$ Daniela Aparecida Uemoto ${ }^{4}$
}

RESUMO

$O$ objetivo deste estudo foi avaliar o efeito da hipertermia no dia da inseminação artificial (IA) até o $13^{\circ}$ dia de gestação, sobre o desempenho reprodutivo de leitoas e porcas. No experimento 1, as 488 fêmeas foram divididas em dois grupos de acordo com a temperatura retal no dia da primeira inseminação artificial (IA), respectivamente, $G 1=\leq 39,5^{\circ} \mathrm{C}$ (normotermia) e $\mathrm{G} 2=>39,5^{\circ} \mathrm{C}$ (hipertermia). As fêmeas com hipertermia apresentaram taxas de retorno ao estro (TRE) maiores e taxas de parto (TP) e tamanho de leitegada (TL) menores $(p<0,05)$, quando comparadas às fêmeas com normotermia. No experimento 2, as 764 fêmeas foram classificadas em quatro grupos, respectivamente, $G 1=$ hipertermia no dia da IA; G2 = hipertermia em um dos primeiros 4 dias após a IA; G3 = hipertermia em pelo menos um dia nos dois períodos anteriores e G4 = hipertermia do $10^{\circ}$ ao $13^{\circ}$ dia de gestação. Fêmeas com hipertermia no dia da primeira IA e no período inicial de gestação apresentaram maior TRE e menor TP no $G 1$ e $G 2(p \leq 0,01)$ e o $T L$ foi menor $(p<0,01)$ nos grupos $G 1$, G2 e G3, quando comparado às fêmeas com normotermia. $\mathrm{Na}$ fase de ligação embrio-maternal (G4), não foram observadas diferenças entre as fêmeas com normotermia e hipertermia. $O$ experimento 3, no qual foram acompanhadas 102 leitoas, das quais 88 foram abatidas aos 29-34 dias de gestação, mostrou uma maior taxa de retorno ao estro (TRE) $(p \leq 0,01)$ e menor taxa de prenhez (TPr) $(p \leq 0,05)$, além de um menor número médio de embriões viáveis (NEV) e menor taxa de sobrevivência embrionária (SE) ( $p<0,05)$, nas leitoas com hipertermia. Com base nesses resultados, pode-se concluir que fêmeas com hipertermia no dia da IA e nos primeiros quatro dias após, podem apresentar prejuízos para o desempenho reprodutivo.

Palavras-chave: suínos, temperatura corporal, eficiência reprodutiva.
SUMMARY

The objective of this study was to evaluate the effect of hyperthermia at the day of artificial insemination (AI) up to day $13^{\text {th }}$ on reproductive performance of gilts and sows. In the experiment 1, 488 females were divided in two groups according to the rectal temperature: $G 1=\leq 39.5^{\circ} \mathrm{C}$ (normothermia), and $G 2$ $=>39.5^{\circ} \mathrm{C}$ (hiperthermia). The females having hyperthermia showed higher return to estrus rate (ERR), and lower farrowing rate $(F R)$ and litter size $(L S)(p<0.05)$ than females having normothermia. In the second experiment, 764 females were grouped in four groups: $G 1$ = hyperthermia on the day of $A I ; G 2$ = hyperthermia on one of the first four days after AI; G3 = hyperthermia in one day of the first two groups, and, G4 = hyperthermia betwen 10-13 ${ }^{\text {th }}$ day of pregnancy. Females having hyperthermia at the day of the first AI and during the first four days after AI, had a higher ERR and lower FR ( $p<0.01)$ in G1 and G2, and lower LS in G1, G2 and G3 ( $p<0.01)$, than the females with normothermia. There were not differences among the females havig hyperthermia or normothermia in G4. In the experiment 3, from 102 gilts, 88 were slaughtered from 29 to 34 days after AI. The ERR were higher $(p<0.01)$ and the pregnant rate $(P R)$ at up to 24 days, the number of viable embryos (NVE) and the embryo survival rate (ESR) were lower in females having hyperthermia $(p<0.05)$. In conclusion, hyperthermia at the day of the first AI and during the first four days after AI can be deleterious to the female reproductive performance.

Key words: swine, body temperature, reproductive efficiency.

\section{INTRODUÇÃO}

O desempenho reprodutivo (DR) em suínos pode ser avaliado tendo como base o número

\footnotetext{
${ }^{1}$ Médico Veterinário, Departamento de Medicina Veterinária, Professor Adjunto, Faculdade de Veterinária, Universidade Federal do Rio Grande do Sul, 91540-000, Porto Alegre, RS. E-mail: ivowentz@ vortex.ufrgs.br. Autor para correspondência.

${ }^{2}$ Médico Veterinário, MsC., Perdigão Agroindustrial, AS, Videira, SC e Rio Verde, GO.

${ }^{3}$ Engenheiro Agrônomo, Pesquisador III, EMBRAPA-Suínos e Aves, Concórdia, SC.

${ }^{4}$ Médico Veterinário, MsC., autônomo.
} 
de leitões produzidos por fêmea ao ano. Esse índice é influenciado diretamente pelo número de partos que cada matriz produz ao ano e pelo número de leitões desmamados por leitegada. Uma série de fatores como genótipo, sanidade, nutrição, manejo e ambiente podem, entre outros, influenciar o DR do rebanho.

Entre os fatores mais importantes, relacionados ao conforto oferecido pelo sistema de alojamento e pela capacidade de produzir distúrbios reprodutivos, estão a temperatura, a umidade relativa e a capacidade de troca de ar, ou a ventilação. As altas temperaturas ambientais, que ocorrem em algumas épocas do ano, deixam os suínos fora de sua zona de conforto térmico, o que, muitas vezes, é capaz de causar transtornos na DR (TEAGUE $\boldsymbol{e} \boldsymbol{t} \boldsymbol{a l}$., 1968). Frente a essas situações de estresse térmico, o sucesso no manejo reprodutivo pode ser afetado por reduções no consumo de ração, dificuldades na detecção de estro, diminuição na taxa de concepção e aumento na mortalidade embrionária (EDWARDS et al., 1968; OMTVEDT et al., 1971). Como conseqüência da temperatura ambiental elevada, EDWARDS et al. (1968) observaram um aumento da temperatura corporal no suíno adulto. BRANDT et al. (1995) sugerem que, durante o período de calor, algumas fêmeas apresentam maiores dificuldades de eliminar o calor corporal, levando a quadros de hipertermia. Dependendo do momento em que essas elevações de temperatura ocorrem, podem afetar a sobrevivência dos conceptos, principalmente na fase inicial da gestação (EDWARDS $\boldsymbol{e t}$ al., 1968; OMTVEDT $\boldsymbol{e t}$ al., 1971). EINARSSON et al. (1996) observaram que o efeito de altas temperaturas ambientais sobre a sobrevivência embrionária depende da temperatura em si e da duração do período de calor aos quais as fêmeas estão submetidas. O efeito de temperaturas ambientais elevadas é mais importante em regiões tropicais e sub-tropicais, onde as temperaturas se mantém elevadas durante vários meses do ano (WETTEMANN \& BAZER, 1985). Assim, também em criações brasileiras, essa situação pode ser encontrada, pelo menos, nos períodos de final da primavera, verão e início do outono, enquanto nos demais períodos essa situação é menos importante.

O objetivo do trabalho foi avaliar o efeito da temperatura corporal na fase inicial da gestação sobre a taxa de retorno ao estro (TRE), taxa de prenhez (TPr), taxa de parto (TP), tamanho da leitegada (TL), número de embriões viáveis (NEV) e taxa de sobrevivência embrionária $(\mathrm{SE})$, em três experimentos.

\section{MATERIAL E MÉTODOS}

Os trabalhos foram conduzidos em duas granjas industriais localizadas no oeste catarinense pertencentes a uma mesma empresa, contando respectivamente com 3500 e 800 matrizes.

Experimento 1: esse experimento foi realizado durante o verão, nos meses de janeiro a março, tendo sido utilizadas 488 fêmeas primíparas e pluríparas da linhagem Camborough $15^{\circledR}$. Após o desmame, as matrizes foram submetidas ao controle de estro duas vezes ao dia com o auxílio de um cachaço adulto. Foram utilizadas somente fêmeas que manifestaram estro até o $6^{\circ}$ dia após o desmame. Aquelas que manifestaram estro após esse período foram excluídas devido ao pequeno número. As fêmeas receberam três inseminações artificiais (IAs), dentro do protocolo normal de IAs adotado pela granja, sendo a primeira realizada no turno seguinte ao início do estro, e as demais nos dois turnos subsequentes, em intervalos de 8 a 16 horas. As doses inseminantes foram armazenadas por um período inferior à $48 \mathrm{~h}$ e continham $4 \times 10^{9}$ espermatozóides, e como diluente foi empregado o Beltsville Thawing Solution (BTS) (JOHNSON et al., 1988). Nesse experimento, a temperatura retal (TC) foi medida na manhã do dia da primeira inseminação artificial (IA). Para a análise dos dados, os animais foram categorizados em dois grupos de acordo com a TC, a partir da TC média dos animais experimentais $\left(39,0^{\circ} \mathrm{C} \pm 0,5^{\circ} \mathrm{C}\right)$. No primeiro grupo (G1), foram agrupadas as fêmeas com TC igual ou inferior a $39,5^{\circ} \mathrm{C}(\mathrm{n}=424)$ e, no segundo grupo (G2), as que tiveram $\mathrm{TC}$ superior a $39,5^{\circ} \mathrm{C}(\mathrm{n}=64)$. As fêmeas foram acompanhadas até o parto subsequente avaliando-se a TRE, TP e TL. As freqüências das TRE e TP, expressas em percentagem, foram comparadas baseadas na distribuição binomial e analisadas utilizando o qui-quadrado. Para a variável TL, foi aplicada a análise de variância e as médias comparadas pelo teste $\mathrm{t}$ de Student.

Experimento 2: neste experimento, foram acompanhadas 764 fêmeas da linhagem Camborough $15^{\circledR}$, durante os meses de fevereiro a abril. As fêmeas foram submetidas ao controle de estro conforme descrito no experimento 1. Foram incluídas na avaliação somente as fêmeas que manifestaram o estro até o $6^{\circ}$ dia após o desmame. Aquelas que apresentaram estro após esse período não foram utilizadas devido ao reduzido número. Nas fêmeas incluídas no estudo, foi medida a TC duas vezes ao dia (manhã e a tarde), do $1^{\circ}$ ao $4^{\circ}$, e do $10^{\circ}$ ao $13^{\circ}$ dia após a IA (dia zero = início do estro). Foram consideradas normotérmicas, as fêmeas que apresentaram temperaturas iguais ou menores a 
$39,5^{\circ} \mathrm{C}$, e, hipertérmicas, aquelas com temperaturas superiores a $39,5^{\circ} \mathrm{C}$. Todas as fêmeas receberam 3 doses inseminantes, conforme descrito no experimento 1. Para fins de análise, as fêmeas foram classificadas em 4 grupos, de acordo com o período em que apresentaram hipertermia, sendo comparadas com as fêmeas que apresentaram normotermia no mesmo período: no grupo 1 (G1) encontram-se as fêmeas $(n=97)$ que apresentaram hipertermia no dia da primeira IA; no grupo 2 (G2), enquadraram-se as fêmeas $(n=222)$ com pelo menos um quadro de hipertermia do $1^{\circ}$ ao $4^{\circ}$ dia; no grupo $3(\mathrm{G} 3)$, as fêmeas $(n=340)$ com pelo menos um quadro de hipertermia nos dois períodos, e, no grupo 4 (G4), as fêmeas $(n=178)$ com, pelo menos, um quadro de hipertermia do $10^{\circ}$ ao $13^{\circ}$ dia. Os dados referentes a TRE e TP foram analisados utilizando o quiquadrado e o TL pela análise da variância com comparação das médias pelo teste t de Student.

Experimento 3: esse experimento foi realizado durante os meses de janeiro a março, tendo sido utilizadas 102 leitoas Camborough $22^{\circledR}$. As leitoas foram alojadas em grupos semanais, permanecendo 8 a 9 animais em cada baia. Imediatamente após o alojamento foi iniciado o manejo com machos adultos, alternadamente, duas vezes ao dia, com o objetivo de induzir o primeiro estro. As fêmeas foram reagrupadas após a manifestação do primeiro estro em grupos sincronizados por entrada em estro e inseminadas artificialmente uma vez no segundo estro, entre 8 e 16 horas após o início do mesmo. A TC foi medida três vezes ao dia, nos mesmos horários do diagnóstico do estro e do acompanhamento ultrasonográfico do desenvolvimento folicular (6:00, 14:00 e 22:00 horas). Entre 21 e 24 dias após a inseminação, foi realizado o diagnóstico de gestação através da ultra-sonografia, para determinação da taxa de prenhez (TPr). Até o abate, as leitoas foram observadas quanto a sinais de estro para determinar a taxa de retornos ao estro (TRE). Oitenta e oito leitoas foram abatidas entre 29 e 34 dias após a IA para avaliar o número de ovulações (NOV) e número de embriões viáveis (NEV), analisados pela análise da variância com comparação das médias pelo teste $\mathrm{t}$ de Student, e a taxa de sobrevivência embrionária (SE), comparando as fêmeas com hipertermia $\left(>39,5^{\circ} \mathrm{C}\right)$ e aquelas com normotermia $\left(\leq 39,5^{\circ} \mathrm{C}\right)$ pelo método do qui-quadrado.

\section{RESULTADOS}

Os dados referentes a TRE, TP e TL, do experimento 1 , são apresentados na tabela 1 . Os animais que apresentaram TC igual e inferior a
Tabela 1 - Efeito da temperatura retal (TC) no dia da primeira inseminação artificial sobre a taxa de retorno ao estro (TRE), taxa de parto (TP) e tamanho da leitegada (TL) em fêmeas classificadas em dois grupos de TC.

\begin{tabular}{lclcc}
\hline Grupos & N & $\begin{array}{l}\text { TP } \\
(\%)\end{array}$ & $\begin{array}{l}\text { TRE } \\
(\%)\end{array}$ & $\begin{array}{c}\text { TL(n) } \\
\text { Média DP }\end{array}$ \\
\hline G1 ( $(39,5)$ & 424 & 89,3 & $8,3^{\mathrm{a}}$ & $12,3 \pm 0,31^{\mathrm{a}}$ \\
G2 (>39,5) & 64 & $73,4^{\mathrm{b}}$ & $20,3^{\mathrm{b}}$ & $11,4 \pm 0,26^{\mathrm{b}}$ \\
\hline
\end{tabular}

$\mathrm{a}$, b: na coluna, valores ligados por letras distintas diferem $(\mathrm{p}<0,05)$.

$39,5^{\circ} \mathrm{C}$ (G1), apresentaram a TRE 12 pontos percentuais menor comparada ao G2 $(\mathrm{p}<0,05)$. Conseqüentemente, a TP das fêmeas com normotermia foi superior àquelas com hipertermia ( $\mathrm{p}<0,05)$, respectivamente $89,3 \%$ e $73,4 \%$ para os G1 e G2. Com relação ao tamanho da leitegada, as fêmeas do G2 tiveram uma redução significativa de 0,9 leitões $(\mathrm{p}<0,05)$ quando comparadas ao $\mathrm{G1}$.

Os resultados do experimento 2, referentes à TRE, TP e TL, são apresentados na tabela 2. As fêmeas que apresentaram hipertermia no dia da IA (G1) ou nos quatro primeiros dias após a IA (G2), apresentaram maior TRE $(\mathrm{p}<0,01)$, e, consequentemente, menor TP $(\mathrm{p}<0,01)$, quando comparadas às fêmeas com normotermia desses grupos. No grupo G3, a diferença observada na TRE de 3,3 pontos percentuais menor a favor das fêmeas com normotermia, não foi assegurada estatisticamente $(\mathrm{p}<0,13)$, bem como também, não foi observada diferença na TP $(\mathrm{p}<0,17)$. No grupo G4, as fêmeas com hipertermia apresentaram menor TRE $(p<0,15)$, quando comparadas às fêmeas com normotermia, mas a TP foi maior nas fêmeas com hipertermia $(p<0,08)$. Em relação ao tamanho da leitegada, as fêmeas com hipertermia apresentaram uma redução de 0,$90 ; 0,70$ e 0,70 leitões $(p<0,05)$, respectivamente nos grupos $\mathrm{G} 1, \mathrm{G} 2$ e G3, quando comparadas às fêmeas com normotermia. O TL observado no G4 não diferiu entre os animais com hipertermia e normotermia $(\mathrm{p}<0,95)$.

Os resultados do experimento 3 são apresentados na tabela 3. A temperatura corporal acima de $39,5^{\circ} \mathrm{C}$ apresentada pelas leitoas durante o estro teve um efeito negativo sobre a TRE $(p<0,01)$ e sobre a taxa de prenhez $(\mathrm{p}<0,05)$. Da mesma forma, foi observado um efeito negativo sobre o número de embriões viáveis e a sobrevivência embrionária. As leitoas com hipertermia apresentaram uma redução de 2,40 embriões $(\mathrm{p}<0,05)$, comparadas às leitoas com temperatura igual ou menor que $39,5^{\circ} \mathrm{C}$. Quanto à sobrevivência embrionária, as leitoas com TC acima de $39,5^{\circ} \mathrm{C}$ 
Tabela 2 - Taxas de retorno ao estro (TRE), taxa de parto (TP) e tamanho da leitegada (TL) de fêmeas com normotermia $\left(\leq 39,5^{\circ} \mathrm{C}\right)$ ou hipertermia $\left(>39,5^{\circ} \mathrm{C}\right)$, no período inicial da gestação.

\begin{tabular}{lrrcccccc}
\hline Grupos & $\mathrm{n}$ & $\begin{array}{c}\mathrm{TRE} \\
(\%)\end{array}$ & $\mathrm{p}$ & $\begin{array}{l}\mathrm{TP} \\
(\%)\end{array}$ & $\mathrm{p}$ & $\mathrm{n}$ & $\begin{array}{l}\mathrm{TL} \\
(\mathrm{x})\end{array}$ & $\mathrm{p}$ \\
\hline $\mathrm{G} 1 \leq 39,5^{\circ} \mathrm{C}$ & 667 & 9,2 & 0,01 & 82,8 & 0,01 & 552 & $11,9 \pm 0,23$ & 0,05 \\
$>39,5^{\circ} \mathrm{C}$ & 97 & 17,5 & & 67,0 & & 65 & $11,0 \pm 0,33$ & \\
$\mathrm{G} 2 \leq 39,5^{\circ} \mathrm{C}$ & 542 & 8,1 & 0,01 & 84,3 & 0,01 & 457 & $12,0 \pm 0,24$ & 0,05 \\
$>39,5^{\circ} \mathrm{C}$ & 222 & 15,3 & & 72,1 & & 160 & $11,3 \pm 0,29$ & \\
$\mathrm{G} 3 \leq 39,5^{\circ} \mathrm{C}$ & 424 & 8,7 & 0,13 & 82,6 & 0,16 & 350 & $12,1 \pm 0,25$ & 0,05 \\
$>39,5^{\circ} \mathrm{C}$ & 340 & 12,1 & & 78,5 & & 267 & $11,4 \pm 0,33$ & \\
$\mathrm{G} 4 \leq 39,5^{\circ} \mathrm{C}$ & 586 & 11,1 & 0,14 & 79,4 & 0,08 & 465 & $11,8 \pm 0,28$ & 0,95 \\
$>39,5^{\circ} \mathrm{C}$ & 178 & 7,3 & & 85,4 & & 152 & $11,7 \pm 0,32$ & \\
\hline
\end{tabular}

p - nível mínimo de significância.

tiveram uma redução de $14,7 \%$ na $\mathrm{SE}$ comparadas às leitoas com normotermia $(\mathrm{p}<0,05)$.

\section{DISCUSSÃO}

Embora o suíno seja submetido a vários fatores estressantes durante o período pré e póscobertura, o estresse provocado por temperaturas ambientais elevadas é aparentemente o mais importante em climas quentes (DAWSON et $\boldsymbol{a l}$., 1998). No Brasil, os períodos de calor são mais importantes durante o final da primavera, no verão e no início do outono, tanto na região sul como nas regiões sudoeste e centro-oeste. Os suínos geralmente são susceptíveis a temperaturas ambientais elevadas devido à sua limitada capacidade de eliminação do calor corporal

Tabela 3 - Taxa de retorno ao estro (TRE), taxa de prenhez (TPr), número médio de ovulações (NOV), número de embriões viáveis (NEV) e sobrevivência embrionária (SE) de fêmeas com e sem hipertermia.

\begin{tabular}{|c|c|c|c|c|c|c|c|}
\hline & \multicolumn{3}{|c|}{$\begin{array}{c}\text { Normotermia } \\
\left(<=39,5^{\circ} \mathrm{C}\right)\end{array}$} & \multicolumn{3}{|c|}{$\begin{array}{l}\text { Hipertermia } \\
\left(>39,5^{\circ} \mathrm{C}\right)\end{array}$} & \multirow[b]{2}{*}{$\mathrm{p}$} \\
\hline & $\mathrm{n}$ & & $\%$ & & $\mathrm{n}$ & $\%$ & \\
\hline TRE* & 81 & & 18,5 & & 21 & 42,9 & 0,01 \\
\hline TPr** & 81 & & 87,7 & & 21 & 71,4 & 0,05 \\
\hline & $\mathrm{n}$ & $\mathrm{X}$ & DP & $\mathrm{n}$ & $X$ & DP & \\
\hline $\mathrm{NOV}$ & 66 & 17,0 & $\pm 0,42$ & 12 & 17,2 & $\pm 0,83$ & 0,77 \\
\hline NEV & 66 & 12,2 & $\pm 3,66$ & 12 & 9,8 & $\pm 4,40$ & 0,05 \\
\hline & $\mathrm{n}$ & & $\%$ & $\mathrm{n}$ & & $\%$ & \\
\hline SE & 66 & & 73,1 & 12 & & 58,4 & 0,05 \\
\hline
\end{tabular}

*TRE até o final do experimento, aos 34 dias.

**TPr avaliada aos 21 a 24 dias de gestação (determinada por ultrasonografia).
(EINARSSON et al., 1996), o que leva, conseqüentemente, à hipertermia quando expostos ao estresse do calor (EDWARDS $\boldsymbol{e t}$ al., 1968; KREIDER $\boldsymbol{e t}$ al., 1978; BRANDT et al., 1995). A exposição de reprodutores à temperatura ambiental elevada representa um fator de risco à fertilidade, podendo acarretar distúrbios reprodutivos quando fêmeas são expostas ao estresse térmico durante o estro ou nos primeiros 15 dias após a cobertura (OMTVEDT et al., 1971; EDWARDS $\boldsymbol{e t}$ al., 1968).

Os resultados dos experimentos 1, 2 e 3 mostram que quadros de hipertermia comprometem o desempenho reprodutivo das matrizes, principalmente quando estes se manifestam no dia da cobertura ou nos primeiros dias de gestação. As fêmeas com hipertermia do experimento 1 apresentaram maior TRE, com conseqüente redução na TP, bem como diminuição do TL em até 0,9 leitões. No experimento 2, no qual as fêmeas foram divididas em quatro grupos de acordo com o período em que apresentaram hipertermia, ficou evidente que quadros de hipertermia no dia da IA e nos primeiros quatro dias após afetaram em maior proporção as perdas reprodutivas do que em fases mais adiantadas, ou seja, no início da ligação embriomaternal. Esse efeito pode ser observado da mesma forma no experimento 3, no qual houve redução significativa do número de embriões viáveis e, consequentemente, na sobrevivência embrionária, nas fêmeas que apresentaram hipertermia durante o estro. Segundo EDWARDS et al. (1968), o número médio de ovulações e a sobrevivência embrionária são normais quando leitoas cíclicas são expostas a elevadas temperaturas ambientais antes da cobertura. Entretanto, quando as fêmeas são submetidas ao estresse térmico durante os primeiros 15 dias após a cobertura, a taxa de prenhez e o número de embriões no $30^{\circ}$ dia após a cobertura são reduzidos (EDWARDS et al., 1968; OMTVEDT et al., 1971). KREIDER et al. (1978) e EDWARDS et al. (1968), ao submeterem leitoas ao estresse térmico, observaram aumento da temperatura corporal e taquipnéia, persistindo a hipertermia durante o período de estresse térmico. BRANDT et al. (1995) sugerem que algumas fêmeas, quando expostas a temperaturas ambientais elevadas, apresentam maior dificuldade de eliminar o calor, apresentando, como consequiência, aumento da temperatura corporal. Dependendo do momento em que isso ocorre, pode ser deletério para a sobrevivência dos embriões, ou 
mesmo para a manutenção da gestação. Entretanto, o efeito de altas temperaturas ambientais sobre a sobrevivência embrionária, depende da severidade e duração do período de calor ao qual as fêmeas são submetidas (EINARSSON et al., 1996). Assim, o efeito das altas temperaturas ambientais sobre a reprodução pode ser indireto, alterando o controle endócrino, ou direto sobre os gametas, embriões ou função uterina (WETTEMAN \& BAZER, 1985). Nesse sentido, WETTEMANN et al. (1988) observaram aumento nas concentrações plasmáticas de progesterona e uma diminuição nas de estradiol, nas fêmeas expostas à temperatura ambiental elevada durante oito dias após o estro. Segundo WETTEMANN \& BAZER (1985), o aumento nos níveis de progesterona e redução nos de estradiol seria observado entre 9 e 13 dias de gestação, mas os autores não sabem explicar se a magnitude destas alterações pode ter afetado a taxa de fecundação e sobrevivência embrionária. JINDAL et al. (1996) sugerem, entretanto, que possivelmente o momento em que ocorre o aumento de estradiol pode ser importante para o reconhecimento da gestação. CHANG (1966) e HAWK \& CONLEY (1971) observam que essas alterações nas concentrações desses hormônios esteroidais poderiam alterar o transporte dos gametas no trato genital feminino, bem como as secreções uterinas (BAZER, 1975), afetando, dessa forma, a taxa de concepção e a sobrevivência embrionária. Embora não tenha sido observado efeito da hipertermia na fase da ligação embrio-maternal no experimento 2, TRUJANO \& WRATHALL (1985) observaram, em embriões de 12 e 13 dias de idade, cultivados por 96 horas a temperaturas de 40,5 a $41,0^{\circ} \mathrm{C}$, anormalidades no desenvolvimento embrionário, quando comparados aqueles cultivados à temperatura de $38,0^{\circ} \mathrm{C}$. Segundo GROSS et al. (1989), o estresse térmico pode comprometer o estabelecimento da gestação, devido ao redirecionamento na secreção de prostaglandinas endometriais de uma orientação exócrina para uma endócrina. WETTEMANN $\boldsymbol{e t}$ al. (1988) observaram que as concentrações de prostaglandina foram maiores que $1 \mathrm{ng} / \mathrm{m} \ell$ entre os dias 13-16 após o estro, em 20\% das leitoas controle que estavam prenhes, $60 \%$ nas que estavam prenhes e foram submetidas ao estresse térmico e $100 \%$ nas não cobertas. Os autores sugeriram que o reconhecimento da gestação pode estar alterado em fêmeas submetidas ao estresse térmico, pelo redirecionamento da secreção de $\mathrm{PGF} 2 \alpha$ do útero para a circulação venosa. Esse redirecionamento na secreção de PGF2 $\alpha$, observado nas fêmeas submetidas ao estresse térmico, pode explicar as maiores TRE observadas nas fêmeas com hipertermia nos experimentos 1,2 e 3 . WETTEMANN et al. (1988), ao submeterem leitoas ao estresse térmico entre 8 a 16 dias de gestação, não observaram diferenças na taxa de prenhez, mas as leitoas estressadas apresentaram menos conceptos comparadas as leitoas controle. WETTEMAN \& BAZER (1985), observaram que, em temperaturas ambientais acima de $32^{\circ} \mathrm{C}$ entre os dias 8 e 16 após a cobertura, há uma redução do peso dos conceptos e da viabilidade de sintetizar proteínas, comprometendo a viabilidade do embrião. No experimento 3 , foi observado uma redução de mais de 2 embriões, nas leitoas que apresentaram hipertermia durante o período pré ou pósinseminação e uma menor taxa de sobrevivência embrionária. Possivelmente, uma alteração no momento da elevação da concentração de estradiol plasmático em fêmeas submetidas a estresse calórico está relacionado a maiores perdas embrionárias, bem como o redirecionamento na secreção de prostaglandina a problemas no reconhecimento da gestação.

Deve ser considerado, também, que não somente a temperatura ambiental elevada provoca hipertermia, mas também devem ser incluídas outras causas como, por exemplo, as lesões de casco ou processos infecciosos e inflamatórios no trato gênito urinário. WRATHAL (1975) sugere que fêmeas com processos infecciosos, além da hipertermia, produzem prostaglandinas endógenas capazes de afetar a capacidade de produção de progesterona pelos corpos lúteos e, consequentemente, interferir na sobrevivência embrionária ou mesmo na manutenção da gestação.

\section{CONCLUSÃO}

Fêmeas suínas que apresentam hipertermia no dia da inseminação artificial ou nos primeiros quatro dias após a IA apresentam maiores taxas de retornos ao estro, menores taxas de prenhez e de parto, menor número de embriões aos 30-35 dias de gestação e menor número de leitões nascidos.

\section{REFERÊNCIAS BIBLIOGRÁFICAS}

BAZER, F.W. Uterine protein secretions: relationship to development of the conceptus. Journal of Animal Science, v.41, p.1376-1382, 1975.

BRANDT, G., WENTZ, IVO, BORTOLOZZO, F.P., et al. Efeito da temperatura corporal sobre a eficiência reprodutiva da fêmea suína. In: CONGRESSO BRASILEIRO DE VETERINÁRIOS ESPECIALISTAS EM SUÍNOS, 1995, Blumenau, SC. Anais... Concórdia : ABRAVES e EMBRAPA Suínos e Aves, 1995. 415p. p.129. 
CHANG, M.C. Effect of oral administration of medroxyprogesterone acetate and ethinyl estradiol on the transportation and development of rabbit eggs. Endocrionology, v.79, p.939-948, 1966.

DAWSON, A., PITT, R., PETERS, A.R. Seasonality and reproduction. In: WIESEMAN, J., VALEY, M.A., CHADWICK, J.P. Progress in pig science, Nottingham, UK: Nottingham University, 1998. p.327-342.

EDWARDS, R.L., OMTVEDT, I.T., TURMAN, E.J., et al. Reproductive performance of gilts following heat stress prior to breeding and in early gestation. Journal of Animal Science, v.27, p.1634-1637, 1968.

EINARSSON, S., MADEJ, A., TSUMA, V. The influence of stress on early pregnancy in the pig. Animal Reproduction Science, v.42, p.165-172, 1996

GROSS, T.S., PUTNEY, D.J., BAZER, F.W., et al. Hormons and protein secretion by endometrium from pregnant and cyclic gilts at day 14 after oestrus. Journal of Reproduction and Fertility. v.85, p.541-550, 1989.

HAWK, H.W., CONLEY, H.H. Loss of spermatozoa from the reproductive tract of the ewe and intensification of sperm 'breakage' by progestogen. Journal of Reproduction and Fertility, v.27, p.339-47, 1971

JINDHAL, R., COSGROVE, J.R., AHERNE, F.X., et al. Effect of nutrition on embryonal mortality in gilts: Association with progesterone. Journal of Animal Science, v.74, p.620-624, 1996.
JOHNSON, L.A., AALBERS, J.G., GROOTEN, H.J.G. Artificial insemination of swine: Fecundity of boar semen stored in Beltsville TS BTS, Modified Modena (MM), or MR-A and inseminated on one, three and four days after collection. Zuchthygiene, v.23, p.49-55, 1988.

KREIDER, D.L., WETTEMANN, R.P., JOHNSON, R.K., $\boldsymbol{e}$ t al. Endocrine changes associated with heat stress of gilts after breeding. Bull Okla Agric Exp Stn, v.103, p.219-226, 1978.

OMTVEDT, I.T., NELSON, R.E., EDWARDS, R.L., $\boldsymbol{e}$ t al. Influence of heat stress during early, mid and late pregnancy of gilts. Journal of Animal Science, v.32, p.312-317, 1971.

TEAGUE, H.S., ROLLER, W.L., GRIFO, H.P. Influence of high temperature and humidity on reproductive performance of swine. Journal of Animal Science, v.27, p.408, 1968.

TOMPKINS, E.C., HEIDENREICH, C.J., STOB, M. Effect of post-breeding thermal stress on embryonic mortality in swine. Journal of Animal Science v.26, p.377-380, 1967.

TRUJANO, M., WRATHALL, A.Z. Effects of hipertermia on explants cultured of porcine endometrium. British Veterinary Journal, v.141, p.603-610, 1985.

WETTEMANN, R.P., BAZER,F.W. Inflence of environmental temperature on prolificacy of pigs. Journal of Reproduction and Fertility, Suppl. v.33, p.199-208, 1985.

WETTEMANN, R.P., BAZER, F.W., THATCHER, W.W., $\boldsymbol{e}$ t al. Conceptus development, uterine response, blood gases and endocrine function of gilts exposed to increased ambient temperature. Theriogenology v.30, p.57-74, 1988.

WRATHALL, A.E. Reproductive disorders in pigs. Farnham Royal: Commonwealth Agricultural Bureaux, 1975. 135p.

Ciência Rural, v. 31, n. 4, 2001. 